Geopolítica(s) Revista de estudios sobre espacio y poder ISSN: 2172-3958

https://dx.doi.org/10.5209/geop.75238

\title{
Mediación estatal y transformaciones territoriales en torno a un conflicto por la tierra en Abasto, La Plata (Buenos Aires, Argentina)
}

\author{
Valeria Ana Mosca ${ }^{1}$ \\ Recibido: 28 de febrero de 2021 / Aceptado: 2 de junio de 2021
}

Resumen. En este artículo discutimos la relación entre política pública y territorio. Para ello realizamos una propuesta teórico-metodológica que parte de una concepción crítica del territorio como expresión de relaciones de poder y de la política pública como proceso social amplio en el que interactúan actores de la sociedad civil y actores estatales, que en su devenir genera transformaciones territoriales. A través de la utilización de fuentes primarias y secundarias y basado en una metodología cualitativa, en este artículo analizamos un caso en profundidad. Se trata de un conflicto por la tierra en la localidad de Abasto, La Plata (Buenos Aires, Argentina), donde surge la tensión entre diversos actores por la propiedad y uso de un predio. Las conclusiones arrojan reflexiones de orden teórico sobre las modalidades en las cuales el estado internaliza las demandas de la sociedad civil y cómo ello se cristaliza en el territorio. Para nuestro caso de estudio se evidencia como resultado una dinámica de expansión urbana - protagonizada por sectores excluidos - y retroceso del uso productivo del suelo.

Palabras clave: transformaciones territoriales; política pública; territorialidades; ordenamiento territorial; Argentina.

\section{[en] State Mediation and Territorial Transformations around a Conflict over Land in Abasto, La Plata, Buenos Aires, Argentina}

\begin{abstract}
In this article we discuss the relation between public policy and territory. To reach this aim we make a theoretical-methodological proposal based on a critical conception of territory as an expression of power relations and that see public policy as a broad social process in which civil society actors and state actors interact, which in its turn generates transformations territorial. Through the use of primary and secondary sources and with a qualitative methodology, in this article we deeply analyse a case. It is a conflict over land in the town of Abasto, La Plata (Buenos Aires, Argentina), where tension arises between various actors over the ownership and the use of a property. The conclusions show theoretical reflections on the modalities in which the state internalizes the demands of civil society and how this is crystallized in the territory. For our case of study, it is proved a dynamic of urban expansion - starring excluded sectors - and a decline in productive land use.
\end{abstract}

Keywords: territorial transformations; public policy; territorialities; spatial planning; Argentina.

1 Consejo Nacional de Investigaciones Científicas y Técnicas (CONICET), Universidad de Buenos Aires (UBA), Universidad Nacional Arturo Jauretche (UNAJ) y Facultad Latinoamericana de Ciencias Sociales (FLACSO). Email: valeriamos@gmail.com https://orcid.org/0000-0003-0708-8239 


\title{
[pt] Mediação estatal e transformações territoriais em torno de um conflito pela terra em Abasto, La Plata (Buenos Aires, Argentina)
}

\begin{abstract}
Resumo. Neste artigo, discutimos a relação entre políticas públicas e território. Para tanto, fazemos uma proposta teórico-metodológica que parte de uma concepção crítica do território como expressão das relações de poder e das políticas públicas como um amplo processo social em que interagem atores da sociedade civil e atores do Estado, que por sua vez gera transformações territoriais. Por meio de fontes primárias e secundárias e com base em uma metodologia qualitativa, neste artigo analisamos um caso em profundidade. Trata-se de um conflito pela terra na cidade de Abasto, La Plata (Buenos Aires, Argentina), onde surgem tensões entre vários atores sobre a posse e o uso de uma propriedade. As conclusões lançam reflexões teóricas sobre as modalidades em que o Estado internaliza as demandas da sociedade civil e como isso se cristaliza no território. Para nosso estudo de caso, o resultado é uma dinâmica de expansão urbana - protagonizada por setores excluídos - e um retrocesso no uso produtivo do solo.
\end{abstract}

Palavras-chave: transformações territoriais; política pública; territorialidades; planificação territorial; Argentina.

Sumario. Introducción. 1. Propuesta teórico-metodológica. 2. Estudio de caso: el conflicto por la tierra en la localidad de Abasto, La Plata (Buenos Aires, Argentina). 2.1. Descripción del conflicto. 2.2. Periodización de los hechos. 2.3. Los "resultados" del conflicto. 3. Política pública y transformaciones territoriales en el conflicto por la tierra de Abasto, La Plata (Buenos Aires, Argentina). 3.1. Política pública: modalidades de acción en el estudio de caso. 3.2. Transformaciones territoriales resultantes del proceso de política pública. Reflexiones finales. Agradecimientos. Referencias.

Cómo citar: Mosca, V. A. (2021). Mediación estatal y transformaciones territoriales en torno a un conflicto por la tierra en Abasto, La Plata (Buenos Aires, Argentina). Geopolítica(s). Revista de estudios sobre espacio y poder, 12(2), 305-327. https://dx.doi.org/10.5209/geop.75238

\section{Introducción}

En las últimas décadas la Región Metropolitana de Buenos Aires atravesó una serie de transformaciones territoriales profundas. Entre sus principales expresiones identificamos las problemáticas de competencia por el uso y propiedad de la tierra entre diversos actores. En efecto, allí conviven distintos estratos de población con diferencias socioeconómicas notables, actores ligados a actividades económicas que generan problemáticas de convivencia, todo ello con una desconcentrada y descoordinada política pública de ordenamiento y planificación territorial (Mosca, 2019; Mosca, 2020).

Desde la perspectiva que aquí sostenemos, que el rol del Estado sea difuso y poco preciso no significa que no tome una posición al respecto de estas problemáticas, ya que las agencias estatales se expresan por acción u omisión en el marco de un proceso de política pública. Partiendo de esta premisa realizamos una propuesta teórico metodológica que busca identificar, a partir de un estudio de caso concreto, las estrategias y modalidades de acción de la sociedad civil y de las agencias estatales, focalizando en cómo a partir de ello se transforman los territorios.

El caso elegido es un conflicto por el uso y propiedad de la tierra en la localidad de Abasto, La Plata (Buenos Aires, Argentina). A través de la utilización de fuentes primarias - recolectadas mediante entrevistas y observaciones participantes-y secundarias - relevamiento de datos censales y estadísticos, así como sistematización 
de bibliografía existente sobre la temática- y basados en una metodología cualitativa, en este artículo buscamos analizar cómo se expresa la política pública en este conflicto y qué transformaciones territoriales se encuentran asociadas.

Para ello proponemos una estructura expositiva que iniciará con el desarrollo de nuestra propuesta teórico metodológica donde se presenta la operacionalización de los principales conceptos con los que trabajamos. Luego realizamos una breve descripción del conflicto a través de una periodización, para luego realizar el análisis del caso a la luz de nuestra propuesta teórico-metodológica. Por último, expondremos nuestras principales conclusiones.

\section{Propuesta teórico-metodológica}

En este artículo partimos de reconocer al territorio como un "espacio definido y delimitado por y a partir de relaciones de poder" (Lópes de Souza, 1995, p.78). En efecto, ello supone la existencia de una puja entre fuerzas sociales que espacialmente se expresa en la constante dinámica de producción, erosión, destrucción de las relaciones que constituyen al territorio (Raffestin, 1993 [1980]; Sevilla Buitrago, 2014). Utilizamos el concepto de territorialidades para referirnos a la expresión espacial de esas fuerzas sociales que pujan por el control del espacio.

Territorio es un concepto de mayor abstracción que refiere a las relaciones de poder proyectadas espacialmente. A ello refiere Porto Gonçalves al considerar que "el territorio es instituido por sujetos y grupos sociales que se afirman por medio de él. Así, hay, siempre, territorio y territorialidad, o sea, procesos sociales de territorialización" $(2009$, p.13). Pero, a su vez, este autor agrega que "en un mismo territorio hay, siempre, múltiples territorialidades" (Porto Gonçalves, 2009, p.13). Sevilla Buitrago $(2008 ; 2014)$ incluso va un paso más allá, al reconocer el conflicto de intereses inherentes a la sociedad y expresado territorialmente. Al respecto plantea que "podemos hablar de lucha de territorialidades en la medida en que los grupos sociales luchan para imponer, de forma consciente o inconsciente, su propia ordenación del territorio" (Sevilla Buitrago, 2014, p.63).

Hechas estas distinciones, consideramos al territorio como la expresión espacial de relaciones de poder, de la puja entre estrategias para controlar, ocupar e influir el espacio. Estas estrategias las llamamos territorialidades, y se establecen como el conjunto de acciones que mediante el control, influencia y ocupación del espacio buscan transformar, mantener o mediar en las relaciones de poder imperantes. En efecto, cuando las relaciones de poder se modifican, también lo hace la capacidad de determinados actores de influir, ocupar y/o controlar el espacio, generando transformaciones territoriales.

Consideramos que en esta dinámica de producción, erosión, destrucción, sustitución de las relaciones que constituyen al territorio, interviene como actor el Estado. A través de la política pública distribuye recursos entre actores sociales viabilizando o limitando las territorialidades intervinientes en un territorio.

Desde la perspectiva que adoptamos la política pública es un proceso social caracterizado por un conjunto de respuestas (por acción u omisión) que permiten interpretar la toma de posición del Estado respecto a una temática o problemática que genera la movilización de actores de la sociedad civil (Oszlak y O'Donnell, 1995, p.112). De ello se infiere que la política pública puede abordarse como un proceso 
en el que participan actores estatales y de la sociedad civil (o no estatales) y que se orquesta en torno a una cuestión que problematiza la sociedad. Oszlak y O Donnell (1995) plantean que el análisis de política pública desde esta perspectiva "permite una visión del estado 'en acción', desagregado y descongelado como estructura global y 'puesto' en un proceso social en el que se entrecruza complejamente con otras fuerzas sociales" (p.104). Dicho en otras palabras, esta perspectiva de la política pública permite advertir que la relación entre Estado y sociedad civil no puede pensarse en términos de exterioridad.

La dinámica de retroalimentación y reconfiguración de las relaciones de poder inherente a un proceso de política pública genera que las acciones y estrategias de los actores intervinientes sean trastocadas generando, a su vez, transformaciones territoriales, al cristalizarse espacialmente dichas reconfiguraciones. En este trabajo buscamos advertir las transformaciones territoriales asociadas a la política pública surgida en torno a un conflicto por la tierra.

Para el análisis de nuestro estudio de caso hemos operacionalizado los principales conceptos de nuestra investigación: política pública y transformaciones territoriales.

Para política pública, partiendo de la concepción ya referenciada - como un proceso amplio a partir del cual interactúan actores estatales y de la sociedad civil en torno a una cuestión que es problematizada socialmente-, buscamos identificar tipos y modalidades de acción.

En ese sentido, una primera distinción que realizamos es entre actores estatales y actores de la sociedad civil (o actores no estatales). Actores estatales serán aquellos que actúan en representación del Estado (instituciones específicas, ministerios, secretarías, direcciones, funcionarios, jueces, etc.) y, que de acuerdo con Oszlak y O'Donnell (1995), toman decisiones y realizan acciones que se caracterizan porque: son respaldadas por normativas de cumplimiento obligatorio y por el recurso legítimo de recurrir al uso de medios de coacción física para ello; suelen afectar a la sociedad más extensamente que el accionar privado; se constituyen como "nudos" al influir en la definición, contenido y explicación de la posición y acción de los actores de la sociedad civil. Actores de la sociedad civil (o no estatales) serán aquellos que, al contrario, no actúan en representación de instituciones estatales sino en representación de intereses individuales o colectivos de la sociedad civil. Desde esta perspectiva, en el marco de un proceso de política pública las diversas fuerzas de la sociedad civil disputan la toma de posición del Estado frente a una cuestión específica. Por medio de sus acciones, tratan de imponer sus intereses en torno a la cuestión para lograr una toma de posición del Estado favorable y que legitime su accionar. Legitimación que suele ir acompañada de una transferencia de recursos materiales e inmateriales que, en muchos casos, se cristalizan en la creación, transformación o desaparición de instituciones como respuesta a una cuestión socialmente problematizada.

En ese sentido, los actores estatales a través del accionar de sus dependencias, asumen un rol de mediación entre actores de la sociedad civil frecuentemente contrapuestos (Therborn, 2016 [1978], p.268). El Estado, a través de sus instituciones, puede insertarse en un proceso social y desde allí influir sobre el desarrollo de una determinada cuestión asumiendo posiciones que alteran las relaciones de fuerza de los actores involucrados en torno a esa problemática. El carácter que asuma esa mediación - a quien beneficia o perjudica - dependerá, en gran medida, del equilibrio 
entre las fuerzas sociales intervinientes y su capacidad de presión sobre el aparato estatal.

Estas mediaciones pueden expresarse en diversas modalidades de acción, entre las que se destacan la represión y la cooptación (Cortés, 2008). La represión es interpretada aquí en su concepción más básica, identificada con las acciones del Estado ligadas a sus aparatos represivos. Implica el ejercicio de violencia física o amenaza de coerción con el objetivo de lograr obediencia a la voluntad del Estado y silenciar eventuales resistencias al orden establecido (Oszlak, 1982). La cooptación, en cambio, es abordada aquí en un sentido amplio, que implica desestimar definiciones que lo plantean como la interacción entre un ente pasivo y otro activo, en dónde uno es absorbido por otro. Englobamos dentro de este concepto los métodos de captación de apoyos a través de alianzas y coaliciones basadas en compromisos y prestaciones reciprocas (Oszlak, 1982). Dentro de los procesos de cooptación podemos identificar, por ejemplo, acciones de "canalización (o desplazamiento)" a partir de las cuales el Estado busca "postergar las demandas populares y, si resulta demasiado costoso oponerse a ellas, canalizarlas a través de instituciones y procesos que no provoquen rupturas" (Therborn, 2016 [1978], p.275). En cambio, para los actores de la sociedad civil (no estatales), la cooptación implica la posibilidad de influir en el contenido de las políticas públicas ${ }^{2}$. Por último, consideramos como una modalidad de mediación del Estado a la omisión. La inacción frente a una demanda o cuestión, aunque difícil de advertir empíricamente, expresa una forma de respuesta ${ }^{3}$. $\mathrm{Al}$ respecto Ozslak y O'Donnell plantean que la inacción estatal puede estar motivada por "esperar a que la cuestión y la posición de los demás actores estén más nítidamente definidas, dejar que se resuelva en la arena privada entre las partes involucradas o considerar que la inacción constituye el modo más eficaz [...]" (1995, p.15). Pero en todos los casos el ignorar una petición o desestimarla forma parte de las modalidades en las que el Estado responde y procesa las demandas de la sociedad.

Por otra parte, el accionar de la sociedad civil (o no estatal) se caracteriza por la generación de estrategias que, incluso sin proponérselo conscientemente, influyen en el accionar estatal. Al respecto Lópes de Souza $(2008,2010)$ propone la fórmula "con el Estado, a pesar del Estado, contra el Estado" para distinguir las estrategias de la sociedad civil para movilizar sus intereses ${ }^{4}$. De sus aportes se pueden identificar dos modalidades. La acción institucional refiere a prácticas que indican espacios de negociación (y por tanto de aceptación y participación en las alternativas intrasistémicas) con el Estado. La acción directa, en cambio, identifica iniciativas que no

Tanto la represión como la cooptación, implican formas de institucionalizar las demandas de los sectores sociales al expresar modalidades en las que el sistema institucional del Estado las procesa mediante su inclusión (cooptación) o mediante su forzoso aplacamiento (represión). Cualquiera de las mediaciones estará determinada por los equilibrios de fuerza de la lucha social. El grado de organización de los sectores sociales, y la capacidad del Estado de asumir e interiorizar determinadas demandas en su seno, en coyunturas específicas, resultan ejes clave para analizar dichas modalidades.

3 Bachrach y Baratz (1962) han remarcado esto, poniendo el foco en los mecanismos que son utilizados para evitar que un conflicto aflore y mantener fuera del proceso político problemas potenciales. El abordaje de las no decisiones y no acciones, ha sido de vital importancia en el análisis del poder, particularmente al plantear que no intervenir en torno a una problemática o demanda forma parte del repertorio de respuestas posibles.

4 La idea de movilizar intereses surge de discusiones en torno a la noción de movimiento social para identificar el accionar colectivo de un sector social en oposición a otros sectores sociales por el control de recursos en una sociedad (Touraine, 1987). Toda acción colectiva busca, en definitiva, mantener o transformar determinadas relaciones de poder. Las discusiones en relación a esta temática tienen profusos debates que no son el objeto de este trabajo. 
utilizan los canales institucionales propuestos y que buscan resolver problemáticas y necesidades de forma autónoma (Lópes de Souza, 2010, p.29).

En definitiva, consideramos a la política pública como un proceso social en el que interactúan actores estatales y de la sociedad civil con diversas modalidades de acción. Mientras que consideramos que los actores estatales tienen el rol de mediar entre actores de la sociedad civil a través de tres modalidades centrales - la cooptación, la represión y la omisión - los actores de la sociedad civil generan estrategias de acción directa o institucional para influir y disputar la toma de posición del Estado. En este artículo sostenemos que este complejo proceso social se cristaliza espacialmente al trastocarse las relaciones de poder que conforman los territorios generando transformaciones en las territorialidades.

Consideramos que ocurren transformaciones territoriales cuando se transforma la capacidad de los actores de controlar, ocupar e influir un espacio determinado. Es decir, cuando se transforman las relaciones de fuerza entre las territorialidades presentes en un espacio/área determinado. A partir del proceso de política pública la mediación que ejerce el Estado puede viabilizar, limitar o convertir las territorialidades intervinientes y de esa forma generar transformaciones territoriales.

Figura 1. Operacionalización de los principales conceptos

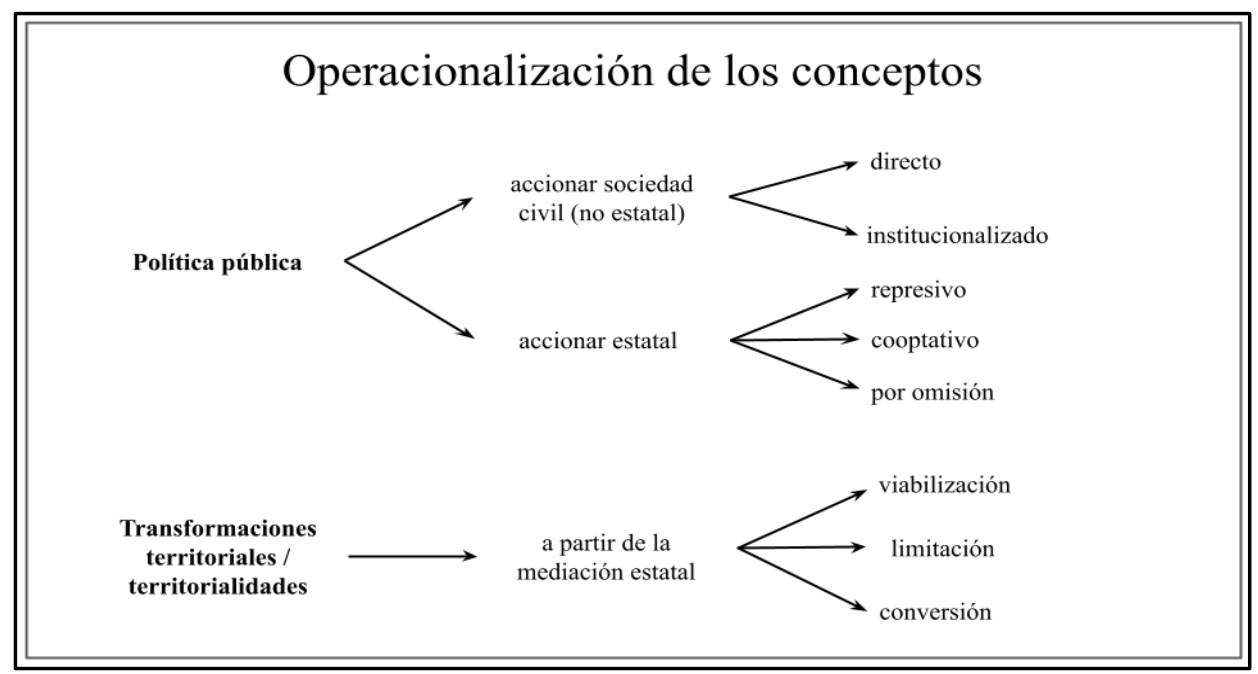

Fuente: elaboración propia.

Consideramos que las territorialidades son viabilizadas a partir de la mediación estatal cuando la intervención de las instituciones estatales legitima, aporta recursos, legisla, en síntesis, facilita a que éste controle, ocupe o influencie un espacio determinado de acuerdo a sus intereses. En sentido opuesto, consideramos que son limitadas a partir de la mediación estatal cuando la intervención de las instituciones estatales, deslegitima, obstaculiza o simplemente omite los intereses de dicho actor respecto a un determinado espacio limitando que éste lo controle, ocupe o influencie. Entre estas situaciones dicotómicas también advertimos que las territorialidades pueden ser convertidas. Referimos a ello para identificar aquellos casos en los cuales la mediación estatal se expresa a través de medidas que buscan transformar los 
intereses que motivan la ocupación, influencia o control de ese espacio para hacerlo compatible con las territorialidades dominantes y a las que ha legitimado en primer lugar.

En la Figura 1 hemos realizado un esquema orientativo de la operacionalización de los conceptos que hemos introducido hasta aquí.

Como ya hemos enunciado, en este trabajo analizaremos el proceso de política pública surgido en torno a un conflicto por la tierra en Abasto, La Plata (Buenos Aires, Argentina) y las transformaciones territoriales asociadas a ello. Con ese fin, en el siguiente apartado realizaremos una descripción de los hechos para luego analizarlos a partir de la propuesta teórico-metodológica expuesta.

\section{Estudio de caso: el conflicto por la tierra en la localidad de Abasto, La Plata (Buenos Aires, Argentina)}

Como hemos advertido en el desarrollo de nuestra perspectiva teórica, la política pública es advertida aquí como un proceso social amplio en torno a una cuestión social que problematiza la sociedad. En nuestro caso analizamos el proceso social tejido en torno a un conflicto por la propiedad y uso de la tierra en un predio en la localidad de Abasto, Partido de La Plata (Buenos Aires, Argentina), en el que intervinieron diversos actores estatales y de la sociedad civil (no estatales) alterando las relaciones de poder que constituyen ese territorio definido por el conflicto.

En tanto estrategia metodológica, el estudio de un conflicto es relevante para nuestros intereses ya que durante sus manifestaciones los actores desarrollan estrategias, proponen discursos, visiones del mundo, definiciones de la situación que permiten construir un corpus susceptible de ser analizado (Melé, 2003), al tiempo que "en estas expresiones de conflicto, con eje en un determinado espacio, es donde podemos encontrar la clave para comprender y explicar las relaciones de poder que se ejercen desde los territorios [...]" (Manzanal, 2007, p.22). La selección de un conflicto, resultó, por lo tanto, una estrategia analítica, ya que a partir de ello se hacen visibles las disputas y el poder.

\subsection{Descripción del conflicto}

Este conflicto se desarrolló en torno al uso y propiedad de un predio de 56 ha, que se ubica en una zona periurbana atravesada por la tensión entre usos rurales y urbanos. En efecto, el terreno en cuestión se encuentra en un ámbito privilegiado dentro del cinturón verde que abastece de alimentos frescos a la Región Metropolitana de Buenos Aires - cercano a vías de circulación y conectado con los diversos mercados concentradores-. A su vez, está lindante con el casco urbano de la localidad de Abasto, sobre una vía asfaltada, donde transitan líneas de transporte público al centro de la Ciudad de La Plata — capital de la Provincia de Buenos Aires y quinto aglomerado urbano del país-, teniendo además buena conexión con la autopista Buenos Aires-La Plata (Figura 2). Ello vuelve al predio "atractivo" para la expansión de fenómenos residenciales, así como para el asentamiento de quintas de producción hortícola, caracterizadas por la presencia de agricultura familiar.

En este caso de estudio advertimos la competencia por la propiedad y uso de este terreno de tres grupos de actores de la sociedad civil (o no estatales) con intereses 
diversos sobre el predio: i) los vecinos urbanos sin tierra ${ }^{5}$ ligados a fenómenos residenciales informales que ocupan el predio como estrategia de acceso a un hábitat y vivienda digna que se organizan en la Asamblea de Legítimos Poseedores de la Tierra y cuyo interés sobre el predio se relaciona con un uso residencial; ii) la inmobiliaria local que dice ser propietaria de los terrenos y cuyo interés en el predio se encuentra relacionado con la obtención de ganancias; iii) diferentes agricultores familiares ligados a la actividad hortícola que arrendaban a la inmobiliaria diversas porciones del predio en donde vivían y trabajaban y cuyo interés sobre el uso del predio era productivo: los Agricultores organizados en la Asociación de Productores Hortícolas Independientes, los Agricultores que a partir del conflicto se organizan en la Asociación Civil 15 de Abril y un grupo de agricultores autónomos que no se encontraban organizados ni se organizan luego a partir del conflicto. Intervienen a su vez una diversidad de actores estatales de nivel nacional, provincial y municipal que median en el conflicto.

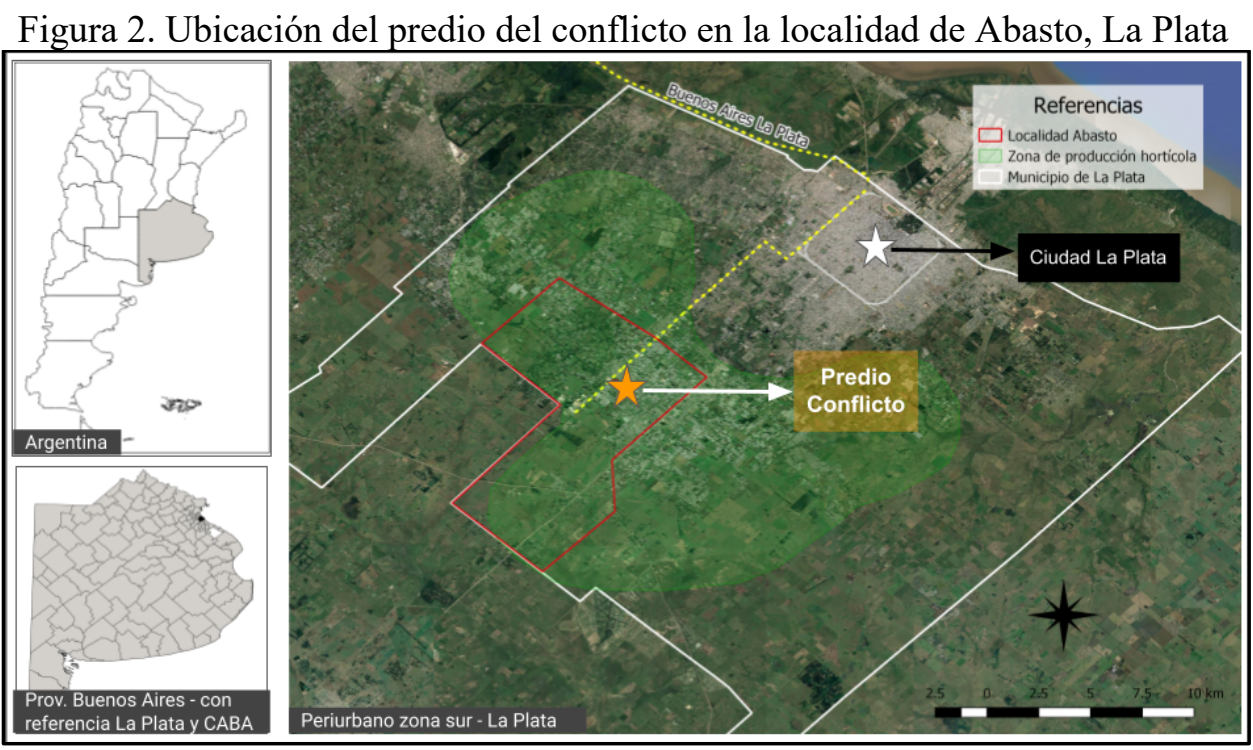

Fuente: Elaboración propia mediante SIG-QGIS Desktop 3.0.3 en base a análisis de información primaria recolectada en trabajo de campo 2015-18.

\subsection{Periodización de los hechos}

En este apartado realizaremos un breve relato del conflicto para luego, a partir de ello, realizar una sistematización de las acciones desarrolladas por los actores de la sociedad civil presentes en el conflicto, así como las acciones de mediación por parte de los actores estatales. Este relato estará organizado a partir de una serie de hitos

5 Se utiliza la expresión "vecinos urbanos sin tierra" para distinguir al sector cuyo interés se encuentra asociado a un uso residencial. Se usa esta expresión para enfatizar que se trató, en su mayoría, de habitantes de la zona y que su interés en estas tierras se asocia a la expansión urbana residencial. A su vez, con la expresión no se busca plantear que los actores ligados a actividades hortícolas asentados en el predio no se consideren "vecinos" de la zona sino, simplemente se trata de una distinción analítica para diferenciar los intereses en pugna en este caso. 
identificados a partir de la intervención del Estado y que marcan una periodización del conflicto.

\subsubsection{Ocupación y desalojo}

A mediados de abril de 2015, parte de un predio de 56 hectáreas fue ocupado por vecinos de la localidad de Abasto que reclamaban tierra para construir sus viviendas. Este hecho fue motivado por la problemática estructural de acceso a tierra para vivienda que atraviesa Argentina en general, y toda la Región Metropolitana de Buenos Aires en particular, a lo que se sumó la existencia de fuertes rumores que circulaban en el barrio respecto de irregularidades en la titularidad de la tierra en cuestión.

En el momento en el que los vecinos realizan la ocupación, en el predio se encontraban viviendo y produciendo alrededor de 20 familias horticultoras que alquilaban la tierra a una importante inmobiliaria tradicional de la zona. Ello implicó la tensión inicial entre estos tres tipos de actores por el tipo de uso y control del territorio.

Frente a esta situación, los vecinos, que habían ingresado a la ocupación de forma individual, deciden organizarse y crear la "Asamblea de Legítimos Poseedores de la Tierra" (en adelante, Asamblea) con el fin de coordinar estrategias y medidas de acción. En contraposición, las veinte familias productoras que se encontraban arrendando este predio no lograron articular una postura común, distinguiéndose entre sí en tres grupos afectados de diversa forma por la toma de tierras, y con posiciones dispares sobre cómo actuar al respecto. En ese contexto, el titular de la inmobiliaria - supuesto propietario de la tierra - realiza una denuncia penal por usurpación hacia los vecinos urbanos organizados en la Asamblea.

En paralelo, este caso va tomando relevancia pública en el contexto de un año electoral ${ }^{6}$. Ello se ve reflejado en la cantidad y variedad de actores estatales que intervienen en este conflicto.

Mientras que en el juzgado donde se presenta la denuncia penal hacia los vecinos, se hace lugar al pedido de desalojo, una vecina organizada en la Asamblea decide pedir una medida de amparo para que se considere su situación de vulnerabilidad. Como respuesta a la solicitud, interviene otro juzgado pidiendo que se suspenda el desalojo y se realicen informes sobre la situación de los ocupantes y la titularidad de las tierras. Frente a esta situación el grupo de productores más afectados por la ocupación - que se desarrollaba sobre la porción del predio que arrendaban-, los Agricultores organizados en la Asociación de Productores Hortícolas Independientes, buscan asesoramiento en el Consultorio gratuito especializado en temáticas rurales dependiente de la Universidad Nacional de La Plata (UNLP). Con el patrocinio de este espacio realizan presentaciones judiciales en los expedientes actuantes en ambos juzgados, manifestando que contaban con contratos vigentes y que, tanto su medio de vida como sus viviendas se encontraban en la zona del conflicto.

Este conflicto cobró particular relevancia y visibilidad en el contexto de la campaña por elecciones nacionales, provinciales y municipales de 2015. Ello generó dentro del Partido gobernante - Partido Justicialista- una fuerte interna que se manifestó a nivel provincial y municipal en dos tendencias divergentes: una asociada a la línea política de la entonces Presidenta Cristina Fernández de Kirchner y otra que expresaba tendencias de diversos referentes dentro del peronismo (entre ellos se destaca la fuerte oposición entre Daniel Scioli, Gobernador de la Provincia de Buenos Aires, y Florencio Randazzo, Ministro del Interior y Transporte de la Nación). 
Luego de diversos intentos de negociación, tanto formal como informal — mesas de diálogo, emisarios de todas las partes interesadas-, para lograr un retiro pacifico del predio y ante la negativa a desocuparlo, se realizó un violento desalojo ${ }^{7}$. Este hecho afectó tanto a los vecinos organizados en la Asamblea como al grupo de agricultores de la Asociación de Productores Hortícolas Independiente, ubicados en la zona del predio que estaba en conflicto. El resto de los grupos de agricultores, al no estar afectados de forma directa por la ocupación, no tomaron medidas en esa instancia, a pesar de que asistieron por asesoramiento al mismo Consultorio jurídico gratuito dependiente de la UNLP.

\subsubsection{La expropiación y las reglamentaciones de uso de suelo}

Luego del desalojo y en conversaciones entre diferentes actores implicados, comenzó a vislumbrarse la posibilidad de expropiar el predio, considerando una importante deuda en concepto de impuestos que el predio poseía con la Provincia de Buenos Aires.

La disputa en esta instancia se encontraba relacionada con el tipo de uso que se privilegiaría de concretarse una expropiación. Participaron de las discusiones al respecto sectores que presionaban para que se priorice el uso residencial, concretando las demandas de los vecinos urbanos organizados en la Asamblea. También intervinieron instituciones y organizaciones vinculadas a los diversos grupos de agricultores familiares tratando de poner de relieve la identidad "hortícola" de la localidad de Abasto, muy ligada a la producción intensiva, para que se preserve el uso productivo del suelo.

Sin embargo, la fuerza de los que demandaban tierras para vivienda - que se expresó a través de la Asamblea, en movilizaciones, cortes de calle, acampes cerca del predio desalojado en reiteradas ocasiones - fueron determinantes: el 13 de mayo de 2015 es aprobada por ambas cámaras de la legislatura provincial la ley de expropiación del predio con finalidad específica de vivienda, desplazando en esta decisión a los agricultores familiares arrendatarios y perjudicando el uso productivo del suelo.

Esta decisión por parte del Estado afectó de lleno a los Agricultores de la Asociación de Productores Hortícolas Independientes, que se encontraban en la zona del predio donde se inició la ocupación. Estos agricultores perdieron la mayor parte de sus posesiones, la producción, el dinero invertido en insumos, al tiempo que automáticamente careció de validez el contrato de arrendamiento de los terrenos donde trabajaban y vivían. En ningún momento se consideró la situación de este actor.

El 9 de junio de 2015, se promulgó la ley de expropiación acompañada por una ordenanza municipal que aplicaba una serie de excepciones al Código de Ordenamiento Territorial (COT) del municipio de La Plata. Allí, además de modificarse el uso residencial para que coincida con la ley de expropiación, se indicaba que una serie de lotes que ocupan 15 hectáreas de ese predio serían destinados para un uso rural-intensivo. Ello significó que, si bien la letra de la ley de expropiación indicaba el uso exclusivo para vivienda, a la hora de aplicar la zonificación de usos se reservaron 15 hectáreas para un uso productivo-intensivo.

La violencia del hecho motivó que la noticia sea retomada por diversos medios nacionales: https://www.lanacion.com.ar/1790864-violento-desalojo-de-un-predio-usurpado o https://www.pagina12.com.ar/diario/socie$\mathrm{dad} / 3-272221-2015-05-08 . h t m l$ 
Ello favoreció a un grupo de 11 familias de la agricultura familiar que no habían sido afectadas ni por la ocupación, ni por el desalojo y que, ante la confusión, aún se encontraban viviendo y produciendo en el predio. Este hecho puso de relieve el accionar contradictorio del Estado, al tiempo que generó interpretaciones ambiguas sobre la potestad de uso en esa zona del predio expropiado.

\subsubsection{El triunfo de los vecinos urbanos sin tierra: estrategias de avance y consoli- dación}

A partir de junio de 2015, los vecinos nucleados en la Asamblea llevaron adelante una estrategia de movilización constante. Entre otras acciones se destaca el acampe permanente que realizaron a la vera del predio expropiado, como un simbolismo de custodia de los terrenos que alojarían sus viviendas. También resaltan las numerosas movilizaciones a la Subsecretaría de Tierras, Urbanismo y Vivienda provincial (institución a cargo de las gestiones de nuevo barrio). Es en este contexto que desde esta institución estatal se crea una mesa de gestión barrial conjunta en la que participa los vecinos de la Asamblea para colaborar en las gestiones de avance de la urbanización.

Una de las primeras acciones que se realizaron en el marco de esta mesa de gestión fue la depuración de un censo que se había realizado al inicio de la ocupación en el mes de abril. La secretaría participó activamente de esta acción con el fin de comenzar a realizar los loteos. También se llevaron adelante diversas conversaciones con un grupo de agricultores familiares - los que hemos identificado como autónomos o no organizados - que aún permanecían en un sector del predio destinado a viviendas. Cada una de estas familias agricultoras negoció su retiro de forma individual con la mesa de gestión barrial. En algunos casos se llegó a acuerdos que implicaron la inclusión en los censos para la adjudicación de un lote en el futuro barrio. En ese sentido, este grupo de agricultores modifican su rol e interés sobre el predio.

A principios de diciembre de 2015, ante un inminente cambio de gestión a nivel nacional, provincial y municipal ${ }^{8}$, las autoridades decidieron "pre-adjudicar" los lotes a los vecinos. Tomaron posesión de sus tierras el 09 de diciembre de 2015, de forma prematura, dado que los tiempos administrativos suelen ser más largos para el trabajo de loteo y pre-adjudicación. En definitiva, la nueva coyuntura política, generó un contexto de mayor presión por parte de los vecinos organizados en la Asamblea para que se les entregue alguna certificación de los acuerdos sostenidos desde junio de 2015 y en el marco de la mesa de gestión barrial.

Recién para el mes de julio de 2017, un año y medio después y en el marco de la campaña para las elecciones legislativas de medio término, la nueva gestión designó presupuesto para la infraestructura del barrio. En efecto, el Ministerio del Interior, Obras Públicas y Vivienda de la Nación destinó una partida para la urbanización del llamado barrio "Nuevo Abasto". Estas obras se plasmaron en un convenio firmado entre Nación y el Municipio de La Plata para la ejecución de los fondos.

8 En octubre de 2015 María Eugenia Vidal de la Alianza política Cambiemos gana la gobernación de la provincia de Buenos Aires. En línea con ello, en noviembre y luego del balotaje, Mauricio Macri es elegido presidente de la Nación y Julio Garro intendente de La Plata. Ambos de la Alianza Cambiemos. Estos resultados implican un cambio de conducción política en los tres niveles de gobierno para esta jurisdicción. Previo a ello se desempeñaban en esos cargos referentes del peronismo del Frente para la Victoria: Cristina Fernández de Kirchner como Presidenta de la Nación, Daniel Scioli como Gobernador de la Provincia de Buenos Aires y Pablo Bruera como Intendente del Partido de La Plata. 
2.2.4. La resistencia de los Agricultores de la Asociación Civil 15 de Abril: estrategias de permanencia y posibilidad de comodato

En paralelo a los avances en la ocupación y urbanización del barrio, las tareas no afectaron al sector con zonificación para uso rural-intensivo. Allí se asentaba un grupo de agricultores familiares que había apoyado la expropiación del predio y que continuaron produciendo y viviendo allí.

Luego de la expropiación, ante la pérdida de validez de los contratos que sostenían con la inmobiliaria, estos productores llevaron a cabo algunas acciones ante la situación de incertidumbre en la que se encontraban.

En primer lugar, con asesoramiento legal del Consultorio jurídico gratuito dependiente de la UNLP, en 2016 formalizaron la organización que venían sosteniendo "de hecho" al conformar la "Asociación Civil 15 de abril". Por otra parte, se propusieron una estrategia de articulación con organizaciones sociales de la zona, al destinar parte de su producción como donativos para comedores y merenderos. Al mismo tiempo se fueron acercando a una organización de mayor jerarquía, el "Frente Agrario Evita", institución que representa al sector de la agricultura familiar a nivel nacional y del que la Asociación Civil comienza a formar parte.

Este grupo de productores, como organización formalmente establecida, demandaban al Estado que les brinde, al igual que a los vecinos organizados en la Asamblea, algún tipo de certificación que avale su permanencia en el predio. Al respecto planteaban que, en conversaciones informales con la Subsecretaría de Tierras, Urbanismo y Vivienda y la Defensoría del Pueblo de la Provincia de Buenos Aires, habían recibido el compromiso de la realización de un comodato por diez años a su favor.

\subsection{Los "resultados" del conflicto}

En 2015 el Estado intervino en un conflicto por el uso y propiedad de un predio de 56 hectáreas donde se tensionaron los intereses de diversos actores de la sociedad civil. Como resultado se aprobó una ley de expropiación sobre el predio que se destinó para la construcción de un barrio residencial. Lo que favoreció al grupo de vecinos organizados en la Asamblea. A partir de esta mediación estatal se legitimó y viabilizó el interese de este actor sobre ese espacio. Tiempo después, inclusive, se destinaron fondos para comenzar con tareas de urbanización (infraestructura básica y apertura de caminos).

En la actualidad, se está avanzando en la construcción del barrio "Nuevo Abasto" (actualmente con nuevo nombre "Sin Frontera"). Si bien se denuncian retrasos y dificultades, el expediente de la expropiación avanza y los vecinos tienen certificados de pre-adjudicación de los lotes a su nombre, que en algún momento serán traducidos a títulos de propiedad de la tierra.

En paralelo, este caso demuestra que el Estado, en su accionar mediador y contradictorio, también favoreció a un grupo de 11 familias agricultoras que continuaron produciendo y viviendo en un espacio de 15 hectáreas. A raíz de la sanción de una ordenanza de uso de suelo que indicó que ese sector sería para uso rural-intensivo, los vecinos organizados en la Asamblea no pudieron avanzar sobre ese sector, a pesar de que ha habido amenazas en ese sentido. 
Cuadro 1. Acciones en el conflicto de Abasto por tipo de actor, actor y tipo

\begin{tabular}{|c|c|c|c|}
\hline $\begin{array}{l}\text { Tipo de } \\
\text { actor }\end{array}$ & $\begin{array}{c}\text { Grupo } \\
\text { de actor }\end{array}$ & Actor & Acciones en el conflicto \\
\hline \multirow{5}{*}{$\begin{array}{l}\text { Sociedad } \\
\text { Civil (no } \\
\text { estatal) }\end{array}$} & \multirow{3}{*}{$\begin{array}{l}\text { Agri- } \\
\text { cultor } \\
\text { Fami- } \\
\text { liar }\end{array}$} & $\begin{array}{l}\text { Asociación } \\
\text { de Produc- } \\
\text { tores Inde- } \\
\text { pendientes }\end{array}$ & - Presentación en los expedientes \\
\hline & & $\begin{array}{l}\text { Asociación } \\
\text { Civil } 15 \text { de } \\
\text { Abril }\end{array}$ & $\begin{array}{l}\text { - Organización de la acción social } \\
\text { - Diálogo informal con actores del gobierno provincial } \\
\text { - Formalización de la acción colectiva con la creación de la } \\
\text { asociación civil } \\
\text { - Generación de redes: participación en una organización de } \\
\text { mayor jerarquía (Frente Agrario Evita); redes barriales con } \\
\text { donación de alimentos a comedores comunitarios de la zona }\end{array}$ \\
\hline & & $\begin{array}{l}\text { Indepen- } \\
\text { dientes / No } \\
\text { organizados } \\
\end{array}$ & - Mesa de diálogo con ALPA + institución provincial \\
\hline & $\begin{array}{l}\text { Vecinos } \\
\text { urbanos } \\
\text { sin tie- } \\
\text { rra }\end{array}$ & $\begin{array}{l}\text { Asamblea } \\
\text { de Legíti- } \\
\text { mos Posee- } \\
\text { dores de la } \\
\text { Tierra }\end{array}$ & $\begin{array}{l}\text { - Ocupación de tierras } \\
\text { - Organización de la Asamblea } \\
\text { - Dos acampes } \\
\text { - Recurrentes movilizaciones, marchas y cortes de calle } \\
\text { - Presentación de medida cautelar individual de un miembro } \\
\text { - Participación en mesa de negociación previa al desalojo } \\
\text { - Participación en mesa de gestión barrial para la urbaniza- } \\
\text { ción del barrio }\end{array}$ \\
\hline & $\begin{array}{l}\text { Inmobi- } \\
\text { liaria }\end{array}$ & $\begin{array}{l}\text { Inmobiliaria } \\
\text { local }\end{array}$ & $\begin{array}{l}\text { - Denuncia por usurpación y pedido de desalojo } \\
\text { - Participación en mesa de diálogo previa al desalojo }\end{array}$ \\
\hline \multirow{8}{*}{ Estatal } & \multirow{2}{*}{$\begin{array}{l}\text { Nacio- } \\
\text { nal }\end{array}$} & $\begin{array}{l}\text { Asistencia } \\
\text { jurídica gra- } \\
\text { tuita UNLP }\end{array}$ & $\begin{array}{l}\text { - Asesoramiento a todos los grupos de la AF que se encon- } \\
\text { traban en el predio } \\
\text { - Acompañamiento a la conformación de la Asociación Civil }\end{array}$ \\
\hline & & $\begin{array}{l}\text { Min. Inte- } \\
\text { rior, Obras } \\
\text { Públicas y } \\
\text { Vivienda }\end{array}$ & $\begin{array}{l}\text { - Destina presupuesto para la urbanización del llamado ba- } \\
\text { rrio "Nuevo Abasto" en } 2017\end{array}$ \\
\hline & \multirow{5}{*}{$\begin{array}{l}\text { Provin- } \\
\text { cial }\end{array}$} & Policía & - Ejecuta el desalojo \\
\hline & & $\begin{array}{l}\text { Juzgados } \\
\text { provinciales }\end{array}$ & $\begin{array}{l}\text { - Un juzgado autoriza el desalojo } \\
\text { - Otro frena el desalojo y pide informes sobre los ocupantes }\end{array}$ \\
\hline & & $\begin{array}{l}\text { Legislatura } \\
\text { provincial }\end{array}$ & - Dicta la ley provincial de expropiación del predio \\
\hline & & $\begin{array}{l}\text { Subsecreta- } \\
\text { ría Tierras, } \\
\text { Urbanismo } \\
\text { y Vivienda }\end{array}$ & $\begin{array}{l}\text { - Participa en la gestión de la expropiación y posterior loteo } \\
\text { del predio y luego en la urbanización del barrio } \\
\text { - Participa en conversaciones con la Asociación Civil sobre } \\
\text { el comodato }\end{array}$ \\
\hline & & $\begin{array}{l}\text { Defensoría } \\
\text { del pueblo } \\
\text { provincial }\end{array}$ & $\begin{array}{l}\text { - Participa en las negociaciones del conflicto } \\
\text { - Participa de las conversaciones para que los agricultores de } \\
\text { la Asociación Civil logren obtener la firma del comodato }\end{array}$ \\
\hline & $\begin{array}{l}\text { Munici- } \\
\text { pal }\end{array}$ & $\begin{array}{l}\text { Legislatura } \\
\text { Municipal }\end{array}$ & $\begin{array}{l}\text { - Promulga las excepciones al Código de Ordenamiento Te- } \\
\text { rritorial del Municipio de La Plata que acompañan la Ley de } \\
\text { Expropiación } \\
\text { - Participa de la aprobación de los fondos recibidos del Mi- } \\
\text { nisterio del Interior, Obras Públicas y Vivienda de la Nación }\end{array}$ \\
\hline
\end{tabular}

Fuente: elaboración propia en base a análisis información primaria recolectada en trabajo de campo 2015-18. 
A estos productores se les prometió un contrato de comodato con el Estado para oficializar su ocupación, ya que, al momento de finalizar la investigación, aún atravesaban gran incertidumbre al no tener papeles que validen su estancia más que la ordenanza de uso de suelo que no define quienes son los beneficiarios concretos ni la asociación civil ni el nombre de alguno de sus miembros-

\section{Política pública y transformaciones territoriales en el conflicto por la tierra de Abasto, La Plata (Buenos Aires, Argentina)}

Para poder analizar el proceso de política pública que surge en torno a nuestro caso, proponemos identificar el accionar de la sociedad civil (o no estatal) y estatal en torno al conflicto descrito. A partir de ello buscamos establecer un análisis que permita dilucidar, a qué actores benefició y advertir cómo ello afecto el despliegue de las territorialidades generando transformaciones territoriales.

Para ello, en el Cuadro 1 hemos realizado una distinción entre tipo de actor para definir si se trata de actores de la sociedad civil o del Estado, grupo de actor que se relaciona con el tipo de interés que persigue respecto al predio (agricultores familiares — uso productivo — , vecinos urbanos sin tierra — uso residencial—, inmobiliaria —uso especulativo, búsqueda de ganancias_- Estado nacional, provincial o municipal - mediación-), y actor para definir su identificación precisa. Para cada caso hemos listado las acciones llevadas adelante por estos actores en el marco del conflicto, las cuales luego analizaremos.

\subsection{Política pública: modalidades de acción en el estudio de caso}

La política pública supone la interacción de diversos actores. Mientras que los actores sociales no estatales diputan la toma de posición del Estado con los recursos a su alcance para lograr una legitimación de su accionar, los actores estatales ejercen una tarea de mediación entre fuerzas sociales.

Este apartado se encuentra dividido en dos partes. En el primero analizaremos una serie de modalidades ${ }^{9}$ del accionar de la sociedad civil en la disputa por la toma de posición del Estado en torno al uso y propiedad del predio en cuestión. En el segundo apartado analizaremos las modalidades de mediación del Estado al respecto.

\subsubsection{Modalidades del accionar de la sociedad civil (o no estatal)}

Como ya hemos mencionado en el primer apartado, consideramos que las modalidades del accionar de la sociedad civil pueden ser de acción directa o institucionalizada.

Las modalidades de acción directa suponen estrategias que buscan resolver las problemáticas de forma autónoma, sin consensuar - al menos en principio- con los actores estatales. En nuestro estudio de caso hemos reconocido las siguientes:

\footnotetext{
En los estudios de acción colectiva se utiliza frecuentemente la noción de "repertorio" para identificar una serie de prácticas que los movimientos y actores colectivos llevan a cabo de manera regular. De acuerdo con Tilly, "los repertorios son creaciones culturales aprendidas, pero no descienden de la filosofía abstracta ni toman forma como resultado de la propaganda política, sino que surgen de la lucha. Es en la protesta donde la gente aprende" (2002, p.31). Sin embargo, preferimos referirnos a modalidades, ya que la expresión "repertorios" remite a cierta sistematización de prácticas que sin un correcto estudio de la coyuntura pueden suponer análisis ahistóricos.
} 
1. Ocupaciones de tierra: resultan una de las principales modalidades para acceder a tierra para el desarrollo de experiencias de producción social del hábitat $^{10}$ en Argentina. En efecto, se trata una acción que implica la toma de posesión de tierra por fuera de los circuitos institucionales establecidos para ello, sin autorización de propietarios, tenientes o poseedores autorizados y con una perspectiva de largo plazo (Spicker et al., 2009). En nuestro caso de estudio, esta acción fue utilizada por los vecinos urbanos organizados en la Asamblea.

2. Organización de la acción social (acción colectiva): la organización de los actores en torno a intereses y objetivos comunes con el fin de consensuar estrategias, es una de las modalidades de acción directa más recurrentes. Consideramos que, al organizarse, la acción social se convierte en acción colectiva, como expresión de un sector social en oposición a otros por el control de recursos en una sociedad (Touraine, 1987). En nuestro caso de estudio, esta acción fue utilizada por los vecinos urbanos organizados en la Asamblea y los productores de la Asociación Civil 15 de Abril.

3. Acampes: otra modalidad de acción directa de los actores intervinientes en el conflicto fueron los acampes, los cuales surgen como una forma de protesta y visibilización concreta. Los actores se instalan con carpas improvisadas en determinados espacios públicos, durante un tiempo variable hasta lograr sean resultas sus demandas. En nuestro caso de estudio, esta acción fue utilizada en varias oportunidades por los vecinos organizados en la Asamblea.

4. Marchas, manifestaciones y cortes de calle: se trata de protestas callejeras cuyo éxito se mide de acuerdo a la cantidad de gente que participa de ella, bajo eslóganes de unidad y confrontación. A través de estas protestas los actores circulan o se detienen obstaculizando o deteniendo el transito con el fin de reclamar o visibilizar un hecho. En nuestro caso de estudio, esta acción fue utilizada por los vecinos organizados en la Asamblea en diversas oportunidades.

Por otra parte, las modalidades de acción institucionalizadas son prácticas que indican espacios de negociación (y por tanto de aceptación y participación en las alternativas intrasistémicas) con el Estado. En nuestro estudio de caso hemos reconocido las siguientes:

A. Invocación a la intervención judicial: se trata de la solicitud de intervención judicial ante un conflicto de intereses. En ese sentido, prácticamente todos los actores intervinientes en el caso utilizaron esta herramienta con el fin de que se resuelva favorablemente la situación. Los únicos que no han realizado dicha invocación han sido los agricultores familiares que hemos identificado

10 La Producción Social del Hábitat se define como el proceso a través del cual las ciudades son producidas por sus propios habitantes atendiendo a sus necesidades, sin priorizar una finalidad lucrativa. Dentro de ella, se destaca la "autoproducción del hábitat" como la producción de ciudad que se realiza bajo iniciativa y control de sus propios usuarios (Rodríguez et al., 2007, p.17). 
como autónomos, en la medida de que han realizado gestiones de forma individual y directamente con la mesa de gestión barrial.

B. Participación en instancias de diálogo formal e informal: durante el desarrollo del conflicto se abrieron diversas instancias de dialogo formales e informales con actores estatales. Nos referimos a espacios institucionales donde se ponen en común los puntos de vista e intereses en pugna. En algunos casos se trata de instancias espontáneas o que se realizan teniendo en cuenta vínculos pre-existentes entre funcionarios, trabajadores estatales y actores sociales y que involucran la capacidad de "lobby" (o "cabildeo"). En otros casos se trata de mesas de gestión o de resolución de conflictos convocadas formalmente por las dependencias estatales para tratar temas específicos. Todos los actores intervinientes en el conflicto han participado de instancias de diálogo más o menos formales con el fin de resolver su situación de forma favorable hacia sus intereses.

C. Formalización de la acción colectiva: nos referimos aquí al hecho de formalizar mediante su conformación en asociaciones civiles o cooperativas de trabajo a las organizaciones surgidas a partir del conflicto. Se trata de la institucionalización de una estrategia de acción colectiva. Los únicos actores que formalizaron su organización, fueron los agricultores familiares de la Asociación Civil 15 de abril quienes inicialmente no conformaban una asociación formal.

A modo de conclusión preliminar, podemos advertir que se privilegiaron las demandas de los actores que realizaron acciones directas, pero se constata que los actores suelen combinar ambos tipos de modalidad de acción. Por ejemplo, los vecinos organizados en la Asamblea utilizaban modalidades de acción directa para lograr ser oídos o reclamar a las instituciones estatales espacios de diálogo y negociación, lo que implica una combinación de ambas modalidades de acción.

\subsubsection{Modalidades del accionar estatal (o de mediación estatal)}

Ya hemos introducido nuestra consideración respecto al rol de mediación que asumen los actores estatales en el marco de un proceso de política pública que suscita la movilización de actores de la sociedad civil y que, en muchos casos - como el nuestro-, tienen intereses enfrentados. Al respecto hemos planteado que, frente a los intereses de los actores de la sociedad civil, la mediación del Estado puede asumir la forma de represión, cooptación u omisión. En nuestro estudio hemos identificado estos tres tipos de mediación como veremos a continuación:

La mediación represiva es interpretada aquí en su concepción más básica, identificada con las acciones del Estado ligadas a sus aparatos represivos. Implica el ejercicio de violencia física o amenaza de coerción con el objetivo de lograr obediencia a la voluntad del Estado y silenciar eventuales resistencias al orden establecido (Oszlak, 1982). En nuestro caso de estudio la principal acción represiva por parte del Estado fue el desalojo. Definimos a los desalojos como las acciones perpetradas por los aparatos represivos del Estado con el fin de desplazar ocupaciones (permanentes o transitorias) de tierras y propiedades públicas o privadas. Participan diversas agencias del Estado en la realización de estas acciones. Para nuestro caso se destacan el 
accionar del Juzgado que hace a lugar a la denuncia por usurpación dictando el posterior desalojo, y la Policía de la Provincia de Buenos Aires que lo ejecuta.

Por otra parte, la mediación cooptativa engloba una serie de iniciativas amplias que identifican los métodos de captación de apoyos a través de compromisos y prestaciones reciprocas entre actores estatales y no estatales (Oszlak, 1982). En efecto, sostenemos que este tipo de mediación puede dar lugar a que las demandas de los actores sociales sean incorporadas institucionalmente por el Estado. De esta forma los actores sociales tienen la posibilidad de "disputar el Estado" al incorporar sus intereses en el entramado institucional.

Dentro de este tipo de mediación advertimos que existen medidas de apoyo, en las cuales el Estado apoya los intereses y demandas concretas de ciertos actores legitimando su accionar. Esto genera la canalización de las demandas transformando el aparato estatal, ya sea por medio de la creación de nuevas leyes, áreas específicas para atender demandas, transferencia de recursos, etc. En nuestro caso esto se vio en la decisión de expropiar para la realización del barrio que demandaban los vecinos organizados de la Asamblea, o luego la dotación de presupuesto para la urbanización del barrio. Ambas decisiones fueron muestras evidentes del apoyo por parte de las instituciones estatales a las demandas de los vecinos organizados en la Asamblea.

Cuadro 2. Actores según modalidad de acción y de mediación estatal

\begin{tabular}{|c|c|c|c|}
\hline Sector & Actor & Modalidad Acción & Modalidad de mediación estatal \\
\hline \multirow[t]{3}{*}{$\begin{array}{l}\text { Agricultor Fa- } \\
\text { miliar }\end{array}$} & $\begin{array}{l}\text { Asociación de } \\
\text { Productores } \\
\text { Hortícolas Inde- } \\
\text { pendientes }\end{array}$ & $\begin{array}{l}\text { Institucional + di- } \\
\text { recta }\end{array}$ & $\begin{array}{l}\text { Omisión (si bien sufren el desalojo, la } \\
\text { principal forma de mediación estatal } \\
\text { fue la de omitir sus demandas, ya que el } \\
\text { desalojo iba dirigido a los vecinos de la } \\
\text { Asamblea centralmente) }\end{array}$ \\
\hline & $\begin{array}{l}\text { Agricultores au- } \\
\text { tónomos (no or- } \\
\text { ganizados) }\end{array}$ & Institucional & Cooptación mediante el desplazamiento \\
\hline & $\begin{array}{l}\text { Asociación Ci- } \\
\text { vil } 15 \text { de Abril }\end{array}$ & $\begin{array}{l}\text { Institucional + di- } \\
\text { recta }\end{array}$ & Cooptación mediante el apoyo \\
\hline $\begin{array}{l}\text { Vecinos sin } \\
\text { tierra }\end{array}$ & $\begin{array}{l}\text { Asamblea de } \\
\text { vecinos urbanos } \\
\text { sin tierra }\end{array}$ & $\begin{array}{l}\text { Directa + institu- } \\
\text { cional }\end{array}$ & $\begin{array}{l}\text { Cooptación mediante el apoyo (si bien } \\
\text { en una primera instancia sufren el desa- } \\
\text { lojo, luego de ello, el accionar del Es- } \\
\text { tado fue coherente con una serie de me- } \\
\text { didas que apoyaron sus demandas de } \\
\text { construir un barrio en el predio en con- } \\
\text { flicto) }\end{array}$ \\
\hline $\begin{array}{l}\text { Especulativo / } \\
\text { inmobiliaria }\end{array}$ & $\begin{array}{l}\text { Inmobiliaria lo- } \\
\text { cal }\end{array}$ & Institucional & Cooptación mediante el desplazamiento \\
\hline
\end{tabular}

Fuente: elaboración propia en base a análisis información primaria recolectada en trabajo de campo 2015-2018.

También existen medidas de desplazamiento/canalización de las demandas. El Estado busca así crear constantemente alternativas para redireccionar los conflictos. Este desplazamiento implica la creación de alternativas intrasistémicas y negociaciones con los actores con el fin de evitar rupturas en el orden hegemónico. En nuestro caso esto se vio en las acciones que buscaron resarcir los perjuicios ligados al 
accionar de apoyo anteriormente referenciado. La indemnización pagada a la inmobiliaria por la expropiación del predio, así como la negociación en torno a la adjudicación de lotes para los agricultores familiares autónomos, suponen muestras de cómo el Estado buscó desplazar los intereses de estos actores en el predio.

Por último, a pesar de que es difícil de advertir empíricamente, consideramos que la omisión o inacción frente a una demanda es una forma de respuesta y procesamiento del Estado. En nuestro caso consideramos que la acción por omisión implica no tomar en cuenta la postura e intereses de los actores a la hora de definir medidas. Este fue el caso de los agricultores familiares organizados en la Asociación de Productores Hortícolas Independientes, quienes a pesar de haber invocado la intervención judicial para que se considere su situación, fueron perjudicados y no fueron ni resarcidos, ni tenidos en cuenta en las resoluciones.

En el Cuadro 2 hemos resumido lo descrito hasta aquí respecto a las modalidades de acción de los actores intervinientes.

\subsection{Transformaciones territoriales resultantes del proceso de política pública}

Como ya hemos advertido, en la perspectiva que aquí sostenemos consideramos que el territorio es la expresión espacial de relaciones de poder, de la puja entre estrategias para controlar, ocupar e influir el espacio. Estas estrategias, que llamamos territorialidades, se establecen como el conjunto de acciones que mediante el control y ocupación del espacio buscan transformar, mantener o mediar en las relaciones de poder imperantes.

Dentro de las territorialidades que intervienen en la producción de un territorio, consideramos que la del Estado reviste una importancia fundamental. En efecto, la lógica que guía el accionar de sus instituciones, a través de políticas y regulaciones, proveen el sustento para el despliegue del accionar de ciertos actores limitando el de otros. Ante una "cuestión socialmente problematizada" los actores involucrados actúan poniendo en juego sus recursos y estrategias para lograr una resolución favorable a sus intereses. En ese contexto la respuesta del Estado se evidencia como "un conjunto de acciones y omisiones que manifiestan una determinada modalidad de intervención del estado en relación con una cuestión que concita la atención, interés o movilización de otros actores en la sociedad civil" (Oszlak y O'Donnell, 1995, p.112). Este proceso supone la producción, erosión, destrucción de territorialidades al transformar o mantener las relaciones de poder que conforman los territorios.

En este apartado, buscamos identificar las formas que asumieron las transformaciones en las territorialidades a partir de la mediación estatal en el conflicto por el uso y propiedad del predio en cuestión. En ese sentido, consideramos que las territorialidades inicialmente identificadas fueron viabilizadas - cuando la intervención de las instituciones estatales legitimó, aportó recursos, legisló, en síntesis, facilitó a que determinado actor controle, ocupe o influencie un espacio determinado de acuerdo a sus intereses - limitadas - cuando la intervención de las instituciones estatales, deslegitimó, obstaculizó o simplemente omitió los intereses de dicho actor respecto a un determinado espacio limitando que éste lo controle, ocupe o influencie- o convertidas - la mediación estatal se expresa a través de medidas que transforman los intereses que motivan la ocupación, influencia o control de ese espacio para hacerlo compatible con las territorialidades dominantes y a las que ha legitimado-, como veremos a continuación. 


\subsubsection{Territorialidades viabilizadas}

En nuestro caso de estudio, observamos la viabilización de las territorialidades de los agricultores familiares de la Asociación Civil 15 de Abril y de los vecinos organizados en la Asamblea de legítimos poseedores de la tierra. Estos dos actores de la sociedad civil son los que actualmente se encuentran controlando, ocupando e influenciando el predio en cuestión. Ambos cuentan con intereses disimiles, ya que mientras los agricultores sostienen un uso productivo del suelo, los vecinos de la Asamblea avanzan con la construcción de un barrio sobre tierra que antes era para uso productivo.

Al mismo tiempo es preciso destacar que estos actores no cuentan con el mismo nivel de apoyo y legitimación a partir de la mediación estatal. Los vecinos organizados en la Asamblea poseen los papeles de pre-adjudicación de cada lote, en donde figura cada futuro propietario, mientras que los agricultores familiares solo cuentan con la promesa de comodato.

\subsubsection{Territorialidades limitadas}

En el conflicto analizado, consideramos que las territorialidades que fueron limitadas fueron las de la Asociación de Productores Hortícolas Independientes y la de la inmobiliaria local. En ambos casos, estos actores perdieron la capacidad de controlar, ocupar o influir en ese predio luego de la mediación del Estado a favor de la viabilización de otras territorialidades. Sin embargo, mientras que en el caso de los agricultores familiares estos no tuvieron ningún tipo de resarcimiento por ello, en el caso de la inmobiliaria el Estado la indemnizó con una suma de dinero por la expropiación del predio del que era aparentemente propietario ${ }^{11}$.

\subsubsection{Territorialidades convertidas}

Consideramos que la única territorialidad convertida en el conflicto fue la de los agricultores familiares autónomos o no organizados ya que los intereses que motivaban el despliegue de esta territorialidad fueron desplazados. En efecto, se trata de horticultores familiares que hacían un uso productivo de suelo, y que luego del conflicto negocian su incorporación al barrio a través de la pre-adjudicación de un lote. Es a partir de allí que estos agricultores convierten su interés respecto del uso de suelo de productivo a residencial.

En el Cuadro 3 hemos resumido lo planteado hasta aquí: tipo de actor, modalidad de acción privilegiada, modalidad de mediación por parte del Estado y en qué sentido se transformó la territorialidad en el predio estudiado.

Por último, cabe señalar que, así como las territorialidades de los actores de la sociedad civil se ven transformadas por la mediación estatal, la territorialidad estatal se ve constantemente transformada por el accionar de los actores de la sociedad civil, en un proceso contradictorio y dialéctico.

11 Nunca se puso corroborar la veracidad de esta situación, ya que la inmobiliaria no presentó los papeles de propiedad en las instancias judiciales relacionadas directamente con el conflicto, que es la información a la que se tuvo acceso en el marco de la investigación. 
Cuadro 3. Actores según modalidad de acción y de mediación estatal

\begin{tabular}{|l|l|l|l|l|}
\hline \multicolumn{1}{|c|}{ Sector } & \multicolumn{1}{|c|}{ Actor } & $\begin{array}{l}\text { Modalidad ac- } \\
\text { ción de la so- } \\
\text { ciedad civil }\end{array}$ & $\begin{array}{l}\text { Modalidad media- } \\
\text { ción estatal }\end{array}$ & $\begin{array}{l}\text { Transformación } \\
\text { de la territoria- } \\
\text { lidad }\end{array}$ \\
\hline $\begin{array}{l}\text { Agricultor } \\
\text { Familiar }\end{array}$ & $\begin{array}{l}\text { Asociación de } \\
\text { Productores } \\
\text { Hortícolas In- } \\
\text { dependientes }\end{array}$ & Institucional & Omisión & Limitada \\
\cline { 2 - 6 } & $\begin{array}{l}\text { Agricultores } \\
\text { autónomos (no } \\
\text { organizados) }\end{array}$ & Institucional & $\begin{array}{l}\text { Cooptación me- } \\
\text { diante desplaza- } \\
\text { miento }\end{array}$ & Convertida \\
\cline { 2 - 6 } & $\begin{array}{l}\text { Asociación ci- } \\
\text { vil 15 de Abril }\end{array}$ & $\begin{array}{l}\text { Institucional } \\
\text { directa }\end{array}$ & $\begin{array}{l}\text { Cooptación me- } \\
\text { diante apoyo }\end{array}$ & Viabilizada \\
\hline \multirow{2}{*}{$\begin{array}{l}\text { Vecinos sin } \\
\text { tierra }\end{array}$} & $\begin{array}{l}\text { Asamblea de } \\
\text { vecinos por la } \\
\text { tierra }\end{array}$ & $\begin{array}{l}\text { Directa }+ \text { ins- } \\
\text { titucional }\end{array}$ & $\begin{array}{l}\text { Cooptación me- } \\
\text { diante apoyo }\end{array}$ & Viabilizada \\
\hline Especulativo & $\begin{array}{l}\text { Inmobiliaria } \\
\text { local }\end{array}$ & Institucional & $\begin{array}{l}\text { Cooptación me- } \\
\text { diante desplaza- } \\
\text { miento }\end{array}$ & Limitada \\
\hline
\end{tabular}

Fuente: elaboración propia en base a análisis información primaria recolectada en trabajo de campo 2015-2018.

Por ello, consideramos que las instituciones estatales intervinientes en este conflicto, no hubiesen actuado viabilizando la territorialidad de los vecinos organizados en la Asamblea y favoreciendo la permanencia de los agricultores familiares organizados en la Asociación Civil 15 de Abril, si estos actores no hubieran llevado adelante las acciones directas e institucionales que hemos señalado anteriormente. De igual manera, las estrategias y acciones esgrimidas por los actores intervinientes buscaron disputar la toma de posición del Estado al respecto, resultando las más efectivas las esgrimidas por estos dos actores favorecidos por la mediación estatal.

No obstante, cabe señalar que los objetivos de este artículo estuvieron orientados en otro sentido, al analizar cómo se transforman las territorialidades de los actores de la sociedad civil a partir de la mediación estatal en el marco de un proceso de política pública.

\section{Reflexiones finales}

Este artículo busca aportar reflexiones sobre la relación entre política pública y territorio a partir del análisis de un conflicto por el uso y propiedad de la tierra que se seleccionó como caso de estudio.

Construimos la perspectiva teórico-metodológica esbozada en estas páginas, partiendo de la premisa de que la ausencia de un abordaje claro y activo por parte del Estado para resolver una cuestión, no implica la ausencia de una toma de posición al respecto, ya que el accionar del Estado es contradictorio y muchas veces se expresa mediante la omisión. Ello significó retomar una perspectiva de política pública como un proceso social amplio y de interacción entre actores de la sociedad civil y del Estado en torno a una cuestión o problemática. A partir de allí pudimos identificar 
modalidades de acción, intereses, estrategias y territorialidades en la producción del territorio, así como las mediaciones que las instituciones estatales implementaron frente a la contraposición de demandas e intereses en nuestro caso de estudio.

Como primera conclusión advertimos que el Estado tendió a internalizar y favorecer las demandas de aquellos actores que privilegiaron estrategias de acción directa. Sin embargo, en el caso presentado se constata que este tipo de acciones suelen ir combinadas con espacios de negociación con las agencias estatales. Por ejemplo, los vecinos organizados en la Asamblea utilizaban modalidades de acción directa para lograr ser oídos o reclamar a las instituciones estatales espacios de diálogo y negociación, lo que implica una combinación de ambas modalidades de acción.

En el territorio el proceso de política pública se cristalizó dando lugar a dos dinámicas diferenciadas en la transformación de las territorialidades analizadas. Por un lado, identificamos una dinámica que resulta característica en el periurbano de $\mathrm{La}$ Plata: la expansión urbana residencial por sobre el espacio productivo. Aquí referimos a que en el predio que inicialmente se dedicaba a producción en su totalidad, hoy día tan solo continúa en producción una porción menor, lo que evidencia el retroceso del uso productivo ante la expansión urbana. Por otro lado, se expresa una dinámica que resultó novedosa: la expansión urbana residencial en este caso es protagonizada por sectores excluidos de la lógica de expansión dominante, ligada a intereses especulativos y rentísticos, expresada en el surgimiento y consolidación de proyectos residenciales para clases medias y altas.

Ante el conflicto presentado y en términos generales podríamos recomendar la necesidad de desarrollar políticas de ordenamiento territorial integrales, que incorporen medidas de acceso a la vivienda y tierra para producir, que incorporen líneas de protección de entornos productivos, así como el desarrollo de herramientas específicas para la distribución equitativa de la tierra y su uso. Sin embargo, queda en evidencia que más que pensar en términos de falta de políticas, analicemos esa ausencia como una política en sí misma. Recordemos que, en definitiva, el Estado también se expresa por omisión.

\section{Agradecimientos}

Este artículo se realizó en el marco del proyecto PICT 2015-0653 y UBACyT 2015 "Política y Territorio. Interrelación y articulación en el contexto de las políticas públicas para la agricultura familiar. Estudios de caso en las provincias de Buenos Aires y Misiones, desde el 2003". Se agradecen los comentarios de la Dra. Mabel Manzanal que enriquecieron el abordaje teórico metodológico de este trabajo y al Dr. Nahuel Andrés por la revisión de las tablas y figuras.

\section{Referencias}

Ávila Sánchez, H. (2009). Periurbanización y espacios rurales en la periferia de las ciudades. Estudios agrarios-Procuraduría Agraria, (41), 93-123.

Bachrach, P., y Baratz, M. (1962). Two Faces of Power. The American Political Science Review, 56(4), 947-952. 
Barsky, A. (2010). La agricultura de "cercanías" a la ciudad y los ciclos del territorio periurbano. Reflexiones sobre el caso de la Región Metropolitana de Buenos Aires. En A. Svetlitza de Nemirovsky (Coord.), Globalización y agricultura periurbana en Argentina. Escenarios, recorridos y problemas (pp.15-32). Buenos Aires: Serie Monografías de la Maestría de Estudios Sociales Agrarios FLACSO.

Cortés, M. (2008). Movimientos sociales y Estado en Argentina: entre la autonomía y la institucionalidad. Informe final del concurso Gobiernos progresistas en la era neoliberal: estructuras de poder y concepciones sobre el desarrollo en América Latina y el Caribe. Programa Regional de Becas CLACSO

Lópes de Souza, M. (2008). Fobópole: O medo generalizado e a militarização da questão urbana. Rio de Janeiro: Bertrand Brasil.

Lópes de Souza, M. (2010). Com o Estado, apesar do estado, contra o Estado: Os movimentos urbanos e suas práticas espacias, entre a luta institucional e a ação direta. Cidades, 7(11), 13-47.

Lópes de Souza, M. (1995). O territorio: sobre espaço e poder, autonomia e desenvolvimento. En I. de Castro, P. da Costa Gómez y R. Lobato Correa (Coords.), Geografia: conceitos e temas (pp. 77-116). Río de Janeiro: Ed. Bertrand.

Manzanal, M. (2007). Territorio, Poder e Instituciones. Una perspectiva crítica sobre la producción del territorio. En M. Manzanal, M. Arzeno y B. Nussbaumer (Comps.), Territorios en construcción. Actores, tramas y gobiernos, entre la cooperación y el conflicto (pp.15-50). Buenos Aires: CICCUS

Melé, P. (2003). Introduction: conflits, territoires et action publique. En P. Melé, C. Larrue, y M. Rosemberg (Coords.), Conflits et territoires (pp. 7-20). Tours: Presses universitaires François Rabelais

Mosca, V.A. (2019). El periurbano de la Región Metropolitana de Buenos Aires: tension entre soberanía alimentaria y derecho a la ciudad. Revista Huellas - UNLpam, 23(1), 87105

Mosca, V. A. (2020). El rol del Estado en la producción del territorio periurbano de la Región Metropolitana de Buenos Aires: agricultura periurbana y expansión residencial. Revista Interuniversitaria de Estudios Territoriales PAMPA, (19), 55-73

Oszlak, O. (1982). Reflexiones sobre la formación del estado y la construcción de la sociedad argentina. Desarrollo Económico, 21(84), 45-70.

Oszlak, O., y O’Donnell, G. (1995). Estado y políticas estatales en América Latina: hacia una estrategia de investigación. Redes, 2(4), 99-128.

Porto Gonçalves, C. W. (2009). Territorialidades y lucha por el territorio en América Latina. Geografia de los movimientos sociales en América Latina. Caracas: Editorial IVIC.

Raffestin, C. (1993 [1980]). Por uma geografia do poder. São Paulo: Editora Ática S.A.

Rodríguez, M.; Di Virgilio, M.; Procupez, V.; Vio, M.; Ostuni, F; Mendoza, M., y Morales, B. (2007). Producción social del hábitat y políticas en el Área Metropolitana de Buenos Aires: historia con desencuentros. Documento de trabajo- Instituto de investigaciones Gino Germani (IIGG), núm. 49.

Sevilla Buitrago, A. (2008). La ciudad y el eclipse de la experiencia: notas para una historia crítica de la ordenación territorial. Polis, (7), 151-77.

Sevilla Buitrago, A. (2014). Hegemonía, gubernamentalidad, territorio. Apuntes metodológicos para una historia social de la planificación. Empiria Revista de Metodología de las Ciencias Sociales, (27), 49-72.

Spicker, P.; Álvarez Leguizamón, S., y Gordon D. (2009). Pobreza. Un glosario internacional. Buenos Aires: CLACSO Libros (Colección CLACSO-CROP). 
Therborn, G. (2016 [1978]). ¿Cómo domina la clase dominante? Aparatos de Estado y poder estatal en el feudalismo, el socialismo y el capitalismo. Madrid: Siglo XXI.

Tilly, C. (2002). Repertorios de acción contestataria en Gran Bretaña: 1758-1834. En M. Traugott (Coord.), Protesta social. Repertorios y ciclos de la acción colectiva (pp. 1748). Barcelona: Editorial Hacer.

Touraine, A. (1987). El regreso del actor. Buenos Aires: EUDEBA. 